\title{
Perceptions and Experiences of Inequity in The Provision and Utilization of Maternal, Newborn, and Child Health Services in Tigray, Ethiopia: A Qualitative Exploratory Study
}

\section{Alem Desta Wuneh}

School of Public Health, College of Health Sciences, Mekelle University, Mekelle

Afework Mulugeta Bezabih

School of Public Health, College of Health Sciences, Mekelle University, Mekelle

Lars Åke Persson ( $\square$ lars.persson@lshtm.ac.uk)

London School of Hygiene \& Tropical Medicine

Yemisrach Behailu Okwaraji

London School of Hygiene \& Tropical Medicine

Araya Abrha Medhanyie

School of Public Health, College of Health Sciences, Mekelle University, Mekelle

\section{Research Article}

Keywords: Maternal and child health services, Utilization, Perceptions, Inequity, Qualitative, Ethiopia

Posted Date: October 28th, 2021

DOI: https://doi.org/10.21203/rs.3.rs-957702/v1

License: (c) (1) This work is licensed under a Creative Commons Attribution 4.0 International License.

Read Full License 


\section{Abstract \\ Background}

In earlier studies, we could show that rural Ethiopian maternal health services were distributed pro-rich, while child immunization coverage was equitably distributed. Hence, this study aimed at exploring rural Ethiopian mothers' and primary healthcare workers' perceptions of inequities and their causes in the provision and utilization of maternal, newborn, and child health services.

\section{Methods}

The study was conducted from August to December 2019 in two rural districts in Tigray, Ethiopia. We performed 22 in-depth interviews and three focus group discussions with mothers who had given birth the last year before the survey. We also interviewed women's development group leaders, health extension workers at health posts, and health workers at health centers. The final sample was determined based on the concept of saturation. The interviews and focus group discussions were audiotaped, transcribed, translated, coded, and analyzed using thematic analysis.

\section{Results}

Mothers perceived the provision and utilization of antenatal care, facility-based delivery, and care-seeking for sick children inequitably distributed, while immunization was seen as an equitable service. The inequity in providing and utilizing maternal and child health services was linked to the economy, distance, social and cultural norms, health systems, maternal age, and education. Poor implementation of the Government's equity-oriented policies, such as community-based health insurance, was perceived to result in health inequities.

\section{Conclusions}

Mothers and primary health care providers in rural Ethiopia indicated weaknesses in delivering equitable services and reasons for inequitable utilization. The narratives could inform efforts to provide universal health coverage for mothers, newborns, and children. These problems require multisectoral actions to address the identified sources of inequities.

\section{Background}

The provision of equitable maternal, neonatal, and child health services enhances the possibilities to reach the current global goals of universal health coverage for mother and children (1). Equity was not an identified goal or target in the Millennium Development Goals $(2,3)$. Despite global progress in the coverage of health services and maternal and child health indicators, inequities remain a challenge $(4,5)$. 
In response to this problem, equity was prioritized in the goals and targets of the Sustainable Development Goals (6). Inequities in the utilization of African maternal health services have been linked to household wealth, distance between home and health facilities, educational level, maternal age, and rural or urban residence $(1,3)$. Social differences and gender inequities have led to a low utilization of maternal health services $(7,8)$. Efforts to reach disadvantaged groups with maternal, newborn, and child health services need to be guided by data on coverage and different inequality dimensions (9).

Ethiopia has made substantial progress in maternal, newborn, and child health in recent decades. The proportion of pregnant mother attending antenatal services four or more times increased from $12 \%$ in the 2005 Demographic and Health Survey to $43 \%$ in 2019 . Over the same years, facility-based deliveries increased from $5-48 \%$. The under-five mortality rate was 123 per 1000 live births in the 2005 survey and 55 per 1000 in 2019. The neonatal mortality rate changed less - from 39 per 1000 live births in the 2005 study to 30 per 1000 live births in 2019 (10). Despite this progress, inequities in services coverage and different maternal and child health outcomes remain a challenge (11). The coverage of maternal health services and basic immunizations have favored the wealthiest, more educated, and those living in urban areas (10). The Government has committed itself to improve equity through the health extension program and other initiatives (12). The equity focus is relatively new in Ethiopia and was included in the health sector transformation plan (13) after the Millennium Development Goal era. This perspective was prompted by the large social and geographical differences in the coverage of health services (14).

Previous qualitative studies from Ethiopia have mainly focused on barriers to maternal, newborn, and child health services utilization $(15,16)$. Qualitative studies exploring the perceptions of inequities of maternal and child health services are scarce. Moreover, in a recent survey in four Ethiopian regions we found that maternal health services utilization was low and inequitably distributed, favoring the better-off mother. In contrast, basic child immunization coverage was low but equitably distributed (17). These results prompted us to learn more about the experiences and perceived causes of inequity in the provision and utilization of maternal and child health services. We were guided by the conceptual framework on social determinants of health proposed by the World Health Organization (18). We aimed at exploring mothers' and primary health care workers' perceptions of inequity and why inequities existed in the provision and utilization of maternal, newborn, and child health services in rural areas of the Tigray region, Ethiopia.

\section{Methods}

\section{Study setting}

This study was conducted in two districts of Tigray region; Enderta and Saharti Samre. The residents in the districts were farmers and predominantly Christian Orthodox followers. The region has a three-tier health system comprising primary, secondary, and tertiary care. The health system is responsible for providing maternal and child health services, such as antenatal care, facility-based delivery, postnatal care, immunization, and treatment of sick children. The primary care unit includes primary hospitals, 
health centers, and health posts responsible for providing the services for the rural population (19). A health center serves approximately 25,000 people. It is also a referral center and training institution for the health extension workers from health posts that provide preventive, promotive, and selected curative child health services (13). The health extension workers are also supported by the women's development group, which involves six neighboring households in a one-to-five women's network. This network is mainly engaged in promoting and mobilizing women to improve health-seeking behavior and liaise with the health extension workers.

\section{Study design, sampling, and recruitment}

This was a qualitative exploratory study with purposive sampling. We selected four tabias (the lowest administrative unit) from the two districts in consultation with the head of the district health office based on their remoteness; two tabias from far away and two closer to the health center. Participants in the indepth interviews ( 22 women) and focus group discussions ( 27 women) included women who had given birth during the year prior to the interview. Women's development group leaders, and health care workers at different levels were also interviewed. Participating mother were recruited by the health extension workers and women's development group leaders, while the health care workers were recruited by their immediate supervisors. We collected our sample based on the principle of saturation; data collection was completed when no new information or theme were generated (20).

\section{Data collection}

Data were collected from August to November 2019. Three university instructors and researchers with masters' degrees who had prior experience in qualitative data collection and analysis together with the principal investigator collected the data after one-day training. The interviews and focus group discussions were undertaken using a pretested guide prepared in English (Additional file 1) and later translated into the local language, Tigrigna. The field guides were developed by applying the Commission on Social Determinants of Health (CSDH) conceptual framework on social determinants of health (18) and consulting experts in the area. We selected this conceptual framework because of its feasibility and wide use in studies of health inequity. The guide included questions on maternal, newborn, and child health services utilization, any perceived difference between groups in the utilization of services, mother's experiences of the services, and perceived causes of inequity in the maternal, newborn, and child health services utilization. In the process of data collection, the field guides were continuously reviewed and improved.

The in-depth interviews with mother were carried out face-to-face in a separate room in their private homes and with the healthcare workers in their private rooms to ensure privacy. The focus group discussions with mother were held at a nearby health post. Interviews with mothers were conducted first. Following a preliminary analysis of these interviews, the healthcare providers were interviewed, and focus group discussions were conducted. The interviewed mothers were not included in the focus group discussions. The interviews and discussions were conducted in the local language, Tigrigna. 
During the focus group discussions, we tried to establish a rapport to make participants feel comfortable to trustworthily share their perceptions and experiences. The interviewers briefed the participants about the study's purpose and obtained signed consent for participation. All in-depth interviews and focus group discussions were audiotaped, transcribed, and translated. Interviewers met with the principal investigator daily to discuss the emerging information, refine the guides, and ensure consistency in data collection. Focus group discussions and in-depth interviews were applied to triangulate the evidence.

\section{Data analysis}

Data were analyzed using thematic analysis according to the theoretical approaches of Miles \& Huberman (21). We followed a step-by-step analytic strategy; the transcribed data were coded, thematized, and complemented with hand-written field notes. The data collectors did the translation and transcription of the interviews and focus group discussions. The transcription was done word-for-word to capture all voices and reviewed repeatedly to get familiarized with the data. The principal investigator together with the data collectors analyzed the data through discussion, i.e., any disagreements were solved through negotiation. The analysis started during the data collection. This start allowed us to know the nature of the data and determine whether saturation had been reached. The coding was done by attaching an underlying meaning for each line or paragraph of the text. Themes were formed by grouping codes that had similar concepts. Thematic analysis was guided by the conceptual framework for action on the social determinant of health (18). The themes were supplemented by verbatim quotations to present the respondents' perspectives. Atlas's qualitative software (version 7.5.16) was used to store and analyze the data. The coding was reviewed repeatedly, and revisions were made accordingly.

\section{Ethical clearance}

The Institutional Review Board of the College of Health Sciences at Mekelle University, Ethiopia, approved the study (Ref. No.: ERC 1434/2018). The study was performed in accordance with the principles in the Declaration of Helsinki. Informed and written consent was obtained from all interviewees and focus group discussion participants. All respondents were informed that their participation in the study was voluntary and that any data were stored safely without identifiers and only accessed by the involved researchers.

\section{Results}

\section{Characteristics of the in-depth interviewees and focus group participants}

The age of the interviewed women varied between 22 and 40 years. A majority had primary (grades 1-8) level of education. Most focus group participants were between 25 and 34 years old. More than half of the focus group participants ( 16 out of 27 ) had attended primary education while three had no formal education. The healthcare providers were two health extension workers and four health workers from 
health centers and woreda health offices. Four women's development group leaders also participated in the study. Interviews, as well as focus group discussions, had a duration of 45 minutes to two hours.

During the pretesting of field guides, the concept of equity was difficult for mothers to understand. They used to define it in terms of timely service provision and utilization. In the actual data collection, we explained inequity in terms of unfair differences in the utilization of maternal and child health services. We used an equivalent local term fithawnet in service utilization. We asked the respondents if the differences in the utilization were fithawi (fair)? All respondents understood the local term for 'fairness'.

Two major themes emerged from the data: perceptions of inequity in provision and utilization of maternal and child healthcare and perceived causes of healthcare inequity. Below follows a presentation of the results complemented with direct quotes from the respondents.

\section{Perceived inequity in the utilization of maternal, neonatal, and child health services}

Mothers perceived child immunization to be a fairly distributed service. All interviewed mothers reported that their children had been vaccinated. They attributed this completion to the outreach immunization services provided by the health extension workers on vaccination days. An interviewed woman explained this:

In our village, you don't find a child left unvaccinated. They (the health extension workers and women's development group leaders) mobilize us for vaccination. There is no single woman who remains at home during a vaccination day. Vaccination is the most satisfactory service for all mothers in our village. They (the health extension workers) come to our village every month on the day of St. Mary, our leisure day, and vaccinate our children (In-depth interview, woman, age 35).

Also, a focus group participant told:

In vaccination, there is no difference. Because we are told to vaccinate our children 45 days after delivery and we, all mothers, vaccinate our children without any difference (Focus group discussion, woman, age 27).

Most mothers reported that they used the primary healthcare services, although some mothers commented that they did not fully attend the antenatal clinics. They underlined that antenatal care and facility-based delivery were still inequitably distributed. Women's development group leaders considered antenatal care to be most problematic, since pregnant mothers got tired as the pregnancy advanced and lacked money for transportation to the health centers' services. Further, they could not get ambulance transport to a health facility during labor. The health workers also stated that poor mothers from remote places were less likely to attend antenatal care and deliver at health facilities.

The participating mothers reported that they did not receive postnatal care at health facilities after giving birth. Once a woman had delivered safely, there was no reason going back to the health facility for 
control. A woman should visit the health facility if she or her newborn baby experienced any illness or complications, such as postpartum bleeding.

I did not visit the health facility after birth because my baby was fragile. How can I take her to the health center at this age? Here, we don't have the practice of going to health facilities before baptizing our children. Now, my baby is one month and two weeks old. I will take her for vaccination tomorrow (In-depth interview, woman, age 30).

Another woman added:

After birth, I was healthy. Hence, I did not see any reason to visit the health center for a checkup. We (mothers) do not go to the health center if our babies and we are healthy. But we go there if mother and baby are not feeling well (In-depth interview, woman, age 35).

The health workers confirmed that mothers who gave birth did not receive regular postnatal care. A young health extension worker said that mothers came to health posts after delivery to vaccinate their babies only, but not for a health check-up. Another health care provider also noted that mothers who gave birth at the health facility could receive a first postnatal care within 24 hours at the facility. But the subsequent postnatal visits at days 7 and 42 did not happen.

\section{Perceived causes of inequity in the maternal and child health services utilization}

The sub-themes identified were socioeconomic context, lack of access, poor quality health services, and insufficient implementation of equity-oriented interventions.

\section{Socioeconomic Context}

Two major codes emerged under the socioeconomic context as reasons to inequity in maternal, newborn, and child health services utilization: the households' economic resources and parents' education.

Most of the participants linked inequity in the utilization of maternal, newborn, and child health services to lack of economic resources. This prevented poor mothers from visiting the health facilities. Money was needed for transport, including transportation cost of their escorts, food, and buying drugs for their children. Poor mothers could not buy expensive medicines from private pharmacies. The inability to cover these costs discouraged poor mothers from using the health facilities.

The mothers who have money are taking public transport to go to health centers for delivery. However, we (the poor) are forced to give birth at home, though we know that the services are free. It is the lack of money for transportation that is deterring us (the poor mothers) to deliver at the health facilities (In-depth interview, woman, age 22).

The health workers at health centers and health extension workers at health posts also acknowledged the influence of economy on service utilization. 
Those mothers from the wealthiest households were hiring minibuses with 300 Ethiopian birr (USD 8.1) to go to the health facility for antenatal care and delivery. However, mothers from poor households don't have this opportunity (In-depth interview, health extension worker, age 28).

Also, the poor woman doesn't want to seek care at the health facility when her child gets sick because she can't buy drugs. So, what would a poor woman do if she doesn't have money at hand? She can do nothing at all. Days pass and she is thinking of taking the child to a health facility, but fail to seek timely medical care because of lack of money (In-depth interview, woman, age 35).

The respondents considered home delivery to be more common among non-educated women. Women with no education were more likely to drop-out of antenatal care. They associated this with less knowledge and understanding of the benefits of utilizing maternal, newborn, and child health services.

...yes, we, the non-educated mothers, are not delivering at the health facilities. For example, the health extension workers provided me with the cell phone number of ambulance drivers. But I didn't call the drivers because I don't know how to make a phone call. This is happening for all of the non-educated mothers in our village. In labor, I will be compelled to give birth at home, hoping that St. Mary visits me with Her spirit. If I am educated, I will call the ambulance and give birth at the health facility. But, we (noneducated women) cannot make calls to ambulance drivers. So, our literacy level makes us to give birth at home (In-depth interview, woman, age 30).

The interviewed women stated that younger mothers used maternal, newborn, and child health services more than older ones. They associated this difference with modernity and younger women having more education.

...most young mothers today are educated. There are even some mothers who completed grade 10. These educated mothers have a better understanding of the benefits of health services. Hence, the utilization of maternal and child health services is higher among these younger ones (In-depth interview, Women's development group leader, age 58).

\section{Lack Of Access}

All respondents agreed that distance to health facilities and topography caused inequity in maternal, newborn, and child health services utilization. These problem worsened when road conditions were poor, if the area had a mountainous topography, and availability of transport was limited. Many mothers from remote villages did not utilize health facilities for their sick children.

... it (health center) is too far from our home. Those residing near the health facilities or living in urban areas use the health facilities more than us. In our village, let alone a pregnant woman, it is even more challenging for non-pregnant to go to the health facility and seek medication. For example, it took me about three hours to reach the health facility for antenatal care follow-up, six hours, including the back trip. It would be impossible to attend all antenatal care (Focus group discussion, woman, age 40). 
Previously, mothers used traditional stretchers to reach the health facilities for delivery. But today, such service is absent. The women's development group leaders associated this with the seasonal migration of young men to urban areas in search of jobs. Therefore, they were absent when such traditional transportation was needed. If an ambulance was available, the ambulance drivers' unfriendly behavior deterred mothers from utilizing these services to reach health facilities. They stated that drivers did not respond to phone calls or put their cell phones off. As a result, mothers were compelled to deliver at home or on the road to the health facilities.

The interviewed health workers reiterated mothers' opinions on distance as a cause of inequity in healthcare utilization. The health workers had observed that mothers from remote areas attended the first antenatal clinic but failed to return to subsequent follow-ups. A women's development group leader suggested connecting villages to health facilities with roads to reduce the disparity in health services utilization.

Within the sub-theme social and cultural norms we identified lack of husbands' support, mothers' cultural taboos, and mothers' heavy housework that deterred poor mothers from seeking maternal and child health services.

Some participants reported that husbands were not able to support their wives during pregnancy. These days, they migrated to urban areas in search for jobs, leaving their wives without support. This was claimed to be a reason for home delivery.

I had delivered at home because I was alone. My husband was not present at home. He moved to ketema (urban area) in search for a job to bring food to our family (In-depth interview, woman, age 35).

Other respondents reported that some husbands were helpful. They supported their wives by either accompanying them to the health facility for delivery or staying at home caring for their children in their absence. Focus groups participants suggested that a husband should not move away until the pregnant woman gives birth.

Those who are utilizing the health center are those whose husbands are present at home. Husbands encourage their wives to go there. If the woman shows the appointment card to her husband, he allows her to visit the health center. For example, my husband says, you need to go to the health center; I will take care of my children and animals (Focus group discussion, woman, age 27).

The respondents suggested that husbands need to be at home for mothers to receive antenatal care and seek care for their sick children. Husbands should cover their wives' responsibilities at home in their absence, arrange transport, including traditional stretchers, for pregnant women to bring them to health facilities for delivery. Lacking husbands' support reduced their wives' utilization of health services.

The respondents reported that women were always busy with household chores, which could reduce their ability to attend antenatal care. The women's development group leaders described the husbands' 
primary responsibility to make money for their families, sometimes far away from home. This absence from home could affect their wives' health-seeking behavior.

Pregnant mothers here do not have any spare time during their pregnancy. They work until the end of their pregnancy, cooking, caring for their husbands and children, and cleaning the house. They are very busy with their housework. No time to go to the health center (In-depth interview, women's development group leader, age 30).

Women reported cultural limitations if seeking care after delivery. In the local tradition, they were restricted from moving outside of their home after delivery. This limitation made mothers not to attend postnatal care before baptism. They also reported fear of exposing their babies to the evil eye and witchcraft if participating in postnatal care.

It is uncommon to attend the services after delivery. In our village, no single mother attends postnatal care in the nearby health center. The culture doesn't allow us to go out after birth before baptizing our babies (In-depth interview, woman, age 35).

Women's development group leaders and health extension workers had also noted these restrictions.

One health care provider underlined that there was not a single cause of inequity in the utilization of health services; multiple causes were intertwined.

Mothers have multifaceted problems that distance them from the health facilities. First, householdrelated problems, second, limited access to transportation, third, lack of awareness and understanding of the benefits of utilizing the health facilities. When these problems co-exist, they widen the distance between home and health facility. If you are far away from the health facility, you are also distant from the information. Thus, lack of access to roads and lack of information are intertwined with lack of economic resources and inflate the distance to the health facilities (Health worker, age 26).

\section{Quality Of Services}

The participants had a range of experiences of health workers' behavior at the health center. Some had been welcomed and treated with respect, while others had been mistreated. Some of the respondents reported that health workers became unreasonably angry when a mother arrived late, gave birth on the way to the health facilities, or gave birth at home due to the delay of ambulances. They mentioned that the health workers did not listen and understand that the situation had been out of the woman's control. Health workers' bad behavior discouraged some mothers from utilizing the health facilities and getting a facility-based delivery.

I have seen a health care provider snapping a laboring woman. They had to refer her to Mekelle, the regional referral hospital, and then she cried. They (health workers) then said you did not feel ashamed when you got pregnant, but you lost the shame and cried while giving birth. They were just joking with 
her. Also, another female hakim (health worker) came and snapped at the woman for crying. It has never happened to me, but I have seen the health workers mistreating laboring women. Thus, it is fear of mistreatment that is affecting the healthcare seeking behavior (Focus group discussion, woman, age 30).

Many focus group participants stressed that health workers' attitudes negatively affected women's careseeking behavior. Negative experiences could also negatively influence other women's utilization of services.

In contrast, a woman who gave birth at a health center described the health workers who assisted her delivery as very respectful and caring.

The health workers that assisted me at delivery were respectful and caring. Even your mother can't do what the health workers did for you. Today, they (health workers) take the role of our parents in caring for us. They are much worried and highly concerned about your health. For example, I had experienced bleeding while giving birth, but they immediately injected me with a drug and stopped the bleeding. I thank them all for saving my life (In-depth interview, woman, age 26).

Similarly, a women's development group leader expressed health workers' fairness and non-discriminating treatment of women based on her own lived experiences:

The health workers are caring, especially for those poor mothers. I am poor and was referred to Mekelle regional referral hospital. The health care providers there were very caring. Some patients were dressed neatly and had their bedsheets and blankets. But I was served equally to those wealthy patients. I slept at the hospital for about three weeks, and I am satisfied with the services they provided (In-depth interview, women's development group leader, age 39).

All focus group participants and most in-depth interviewees noted that the unavailability of pharmaceutical drugs was a significant concern at government health facilities. The respondents had been told to buy their medicines at private pharmacies when these were lacking at public facilities. This had deterred poor people from using the health facilities.

The healthcare providers wrote a prescription and told us to buy drugs from private pharmacies. We feel distrust when medicines are lacking at government health facilities. How can private pharmacies have a better supply of drugs than the government facilities? (Focus group discussion, woman, age 40).

\section{Insufficient Implementation Of Equity-oriented Interventions}

Some equity-oriented policies, such as community-based health insurance, maternal waiting homes, and ambulance services were reported to be insufficiently implemented, resulting in inequities in services utilization. Health insurance could potentially address the financial barriers for poor mothers. However, the participants reported that they were not benefiting from this intervention. The focus group 
participants suggested that this scheme had become a reason for the drug unavailability because they were told to buy drugs from private pharmacies.

I had a seven-month old infant who was sick, and I brought him to the health facility. They (the health workers) examined him and wrote prescriptions. They told me to buy the drugs from a private pharmacy. I showed my insurance card, but they didn't respond. I went back home without having any drugs because I didn't have any money. Health insurance is worthless (In-depth interview, woman, age 25).

The respondents were aware of the maternal waiting homes, but did not accept these services because of lack of water, food, and electricity. Some mothers also mentioned that there was nobody at home who could care for their other children and animals if waiting to deliver at the health facility. Therefore, they preferred not to stay at those maternity waiting homes.

The women's development group leaders mentioned that their role in promoting the use of health facilities had weakened because of inadequate contact and supervision from the health extension workers. They believed their contributions potentially to be significant in creating demand for health facility utilization by increasing awareness and mobilizing women within their network. They used to support mothers from all social groups. Mothers appreciated their support, especially during pregnancy and at delivery.

Our (women's development group leaders') work is deteriorating now. We had a monthly meeting to monitor the activities of the women's development group. In this meeting, we reported those who are delivering at home and who are not attending antenatal care. However, today our role is becoming passive due to weak coordination from the health extension workers. We have reduced the role we used to play in educating and mobilizing mothers to use the maternal and child health services (In-depth interview, women's development group leader, age 39).

\section{Suggestions to improve equity in the utilization of health services}

The respondents emphasized the importance of improving access to maternal, newborn, and child health services by moving the services closer to the community. They noted that the social disparity created because of poor access to health facilities was unfair. One woman, aged 22, suggested that there should be a health facility in each tabia to enhance equitable access to health services. Some suggested upgrading of health posts to health centers by equipping those with the required health workers, pharmaceutical drugs, and other supplies. They also suggested new roads and increased number of ambulances. The respondents wanted the health services to take measures against bad behavior by health workers and ambulance drivers. It was also proposed to support the poor to improve inequity in the utilization of services. A participating woman suggested a green bank to solve the poor households' money problem to cover medical and non-medical expenses.

I would suggest contributing cereals, especially during the harvesting season, and store in one place to support the poor. It is during this season that the farmers can easily get grains. If we contribute at least 
two shember (equivalent to $3 \mathrm{~kg}$ ) a year, it would be adequate to support the poor. The banked cereals could even cover the poor mothers' medical and non-medical expenses (In-depth interview, women's development group leader, age 22).

\section{Discussion}

In this study in rural Tigray, Ethiopia, mothers and primary health care providers perceived differences as unfair in the provision and utilization of maternal health services, antenatal care, skilled birth attendance, postnatal care, and services for sick children. Child immunization was perceived as an equitable service. They identified a number of interrelated reasons to these inequities; poverty and lack of education made it difficult to reach facilities and pay for medicines. Long distance and harsh topography reduced access to services. Cultural norms blocked access to postnatal services. Gender roles prevented mothers from seeking care when husbands were absent. Lack of medicines at health facilities and rude or unfriendly staff experiences prevented mother from visiting health facilities. In contrast, mothers perceived that child immunization services, often provided in outreach activities, resulted in equitable coverage. The informants felt that policy initiatives, such as health insurance, maternal waiting homes, and ambulance services, were equity-oriented but poorly implemented.

A systematic review of equity in utilization of maternal health services in low-income countries from 2005 to 2015 revealed that most studies focused on the level of utilization but less on the social equity in use of services (3). During the Millennium Development Goal era, there was not sufficient attention given to an equity perspective on maternal and child health services utilization. Intersectoral actions are needed to address these disparities that are attributed to social determinants of health (22). In a previous survey in four Ethiopian regions, we could show low and inequitable coverage of maternal health services, favoring the better-off women (17). The present qualitative study results point at a range of interconnected determinants; some within reach for health system actions, others that need improvements in other sectors of society.

Household poverty was considered one of the root causes of inequity in the utilization of maternal and child health services. Other studies from Ethiopia $(23,24)$ and Sub-Saharan African countries $(25)$ have produced similar results. Poor people lack money for transportation to health facilities and to get pharmaceutical drugs $(26,27)$. Out-of-pocket payments may create a financial catastrophe to poor households $(11,28)$ and drive them further into poverty $(29)$ with widened inequity. This shows the close connection between the 2030 target for universal health coverage (Sustainable Development Goal 3) and the goal for poverty elimination defined in Sustainable Development Goal 1 (3). The respondents in our study suggested to initiate community-based self-funding schemes, such as a green bank to bridge the poverty-related equity gap.

Maternal education was brought forward as another explanation to equity or inequity in the utilization of maternal, neonatal, and child health services. Educated women were more likely to use the services. This common finding, appearing in reviews as well as in other qualitative studies in Ethiopia $(27,30)$, relates 
the difference to improved knowledge and understanding of maternal and child health services (31-33) but also to enhanced autonomy $(31,34)$ and decision-making $(1)$. Our informants considered young women to use maternal and child health services more than older women, partly explained by the expansion of education in Ethiopia that could reduce health disparities (35). This links the goal on universal health coverage with access to education, as defined in the Sustainable Development Goal 4 (36). Hence, education contributes to reducing gender-based and educational inequities in healthcare utilization.

Distance to health facilities was seen as another cause of inequity in the access to maternal, newborn, and child health services despite the efforts to improve access through the health extension program (37). Poor mothers from remote areas had difficulties in accessing and using maternal and child health services. There was lack of transportation, roads in poor condition and a mountainous topography (24, $38)$. This is not uncommon also in other African countries $(25,39,40)$. This implies that inequities may be reduced by construction of roads and improving transport services (35). The respondents also suggested strengthening outreach services.

The respondents considered lack of support from husbands and busy mothers as barriers for attending antenatal care and getting facility delivery (41). In settings like Ethiopia, gender inequality (14) causes inequities in the use of the maternal, newborn and child health services $(16,42)$. As gender is socially and culturally constructed, it is obvious that maternal health seeking behavior would be affected by the sociocultural norms $(7,43)$. Other studies from low-income settings show similar results $(43,44)$. So, intervening on gender equity and women's empowerment (Sustainable Development Goal 5) have positive consequences for healthcare utilization, health and development $(7,45)$.

A postnatal visit around the third day after delivery is essential for mothers' and newborns' health (29). The respondents considered a post-natal visit to health facilities only if mother or child were sick or experienced complications. Sociocultural barriers, combined with a lack of awareness of the benefits of preventive services influenced the low coverage of postnatal care $(11,46,47)$. The lack of home visits and counseling in remote rural settings results in no or low coverage of postnatal care $(47,48)$. A way forward could be to strengthen home-based postnatal visits by health extension workers.

The informants gave several examples of the low quality of services, such as improper attitudes, maltreatment, and lack of medicines. Mothers who experienced intimidations did not return to the health facilities, resulting in home deliveries. The unavailability of drugs at the public health facilities, which demanded additional out-of-pocket payments (49), and unfriendly services distanced the poor mothers from utilizing the otherwise free maternal and child health services (49). Other studies from Ethiopia (41, 50) and Sub-Saharan African countries (43) have reported similar findings. Poor quality constrains mothers from using the services, resulting in widened inequity $(51,52)$. Bridging the quality gap would potentially reduce inequity in access and utilization to maternal, newborn, and child health services (52, 53). 
The poorest mothers from remote households were neither benefiting from the community-based health insurance scheme, nor from the maternal waiting homes at health facilities. The maternal waiting homes lacked water, food and electricity. These problems were also shown in a study conducted in other parts of Ethiopia (38). In low- and middle-income countries, the failure to implement government policies and insurance schemes reduce their effectiveness (54). There is a need enhance monitoring and evaluation of the implementation and effectiveness of existing interventions to ensure equitable service utilization.

A review from Vietnam showed that inequity was created as a result of economic constraints, low education, and cultural differences (55). Inequities in utilization of maternal and child health services are found in the interactions between social determinants of health (31) and poorly functioning health systems (56). Thus, addressing poverty (Sustainable Development Goal 1), coverage and quality of education (Sustainable Development Goal 4), ensuring gender equality (Sustainable Development Goal 5), will substantially reduce inequities and contribute to ensuring universal health coverage (Sustainable Development Goal 3) (36). Equity-oriented policies and interventions need to be integrated with social development programs, such as targeting poverty reduction, promoting gender equality and empowerment, and mitigating inequities $(31,54)$. These efforts require multisectoral collaboration and action to reach the sustainable development goals and targets for maternal and child health (1).

\section{Strengths And Limitations}

Our study contributes to the literature on perceptions of inequity in the utilization of maternal, neonatal, and child health services in low-income countries. Including women from rural communities along with health workers allowed us to capture different perspectives and triangulate the evidence. Data were collected from participants in multiple study sites using in-depth interviews and focus group discussion to improve the transferability of the results to other similar settings in Ethiopia. The primary healthcare structure is similar in all agrarian rural regions of the country. There was peer debriefing throughout the data collection and analysis to ensure the validity of the data. Information collected through different qualitative methods were triangulated to enhance credibility. Social desirability bias was a potential threat to the findings. The study participants were selected by the health care providers, which could imply that mothers hesitated to share sensitive information about the health services. However, we tried to minimize this risk by carefully introducing the study, establishing rapport, and presenting issues with follow-up prompting questions.

\section{Conclusion}

Our informants from rural Tigray, Ethiopia, perceived inequities to be common in the utilization of maternal, newborn, and child health services in their communities. Child immunization was an exception, due to the outreach mode of services. Among the leading perceived causes mothers and health workers mentioned poverty, distance, and low quality of services. Equity-oriented policies and health insurance schemes were poorly implemented. As part of the efforts to reach the Sustainable Development Goals, 
interventions to alleviate poverty, enhance education, and gender equality could contribute towards an equitable universal health coverage.

\section{Declarations}

\section{Consent for publication}

Not applicable.

\section{Competing interests}

All authors declare no competing interests.

\section{Funding}

The study was funded by the Bill \& Melinda Gates Foundation (INV-009691) through the London School of Hygiene and Tropical Medicine. The funder had no role in the study design, collection, management, analysis, and interpretation of data.

\section{Availability of data}

The qualitative datasets generated and analyzed during the current study are not publicly available due to confidentiality reasons. De-identified datasets are available from the corresponding author on reasonable request.

\section{Authors' contributions}

$A D$ conceived the idea and designed the study, collected data, did the analysis, drafted and completed the manuscript. AAM, AMB, YO, and LP contributed to the research idea and edited different versions of the manuscript. All authors read and approved the final version of the manuscript.

\section{Acknowledgment}

We thank all participants of this study.

\section{References}

1. Yaya S, Ghose B. Global Inequality in Maternal Health Care Service Utilization: Implications for Sustainable Development Goals. Heal Equity. 2019;3(1):145-54.

2. Degefa T, Hoelscher K. Development aid and health equity in Ethiopia. Dev Stud Res. 2020;7(1):8392.

3. Çalışkan Z, Kılıç D, Öztürk S, Atılgan E. Equity in maternal health care service utilization: a systematic review for developing countries. Int J Public Health. 2015;60(7):815-25. 
4. Dhaliwal LK. Health Equity and Sustainable Development Goals: Role and the Complexity. Springer Nat. 2019;316-24.

5. Countdown to 2030 Collaboration. Review Countdown to 2030: tracking progress towards universal coverage for reproductive, maternal, newborn, and child health. thelancet. The Lancet 2018;6736(18):1-11.

6. Hosseinpoor AR, Bergen N, Schlotheuber A, Grove J. Measuring health inequalities in the context of sustainable development goals. Bull World Health Organ. 2018;96(9):654-9.

7. Morgan R, Tetui M, Kananura RM, Ekirapa-Kiracho E, George AS. Gender dynamics affecting maternal health and health care access and use in Uganda. Health Policy Plan. 2017;32:v13-21.

8. Singh K, Bloom S, Brodish P. Gender Equality as a Means to Improve Maternal and Child Health in Africa. Heal Care Women Int. 2016;36(1):1-12.

9. Boerma T, Requejo J, Victora CG, Amouzou A, George A, Agyepong I, et al. Countdown to 2030: tracking progress towards universal coverage for reproductive, maternal, newborn, and child health. The Lancet. 2018 Apr 14;391(10129):1538-1548.

10. Ethiopian Public Health Institute (EPHI) [Ethiopia] and ICF. Ethiopia Mini Demographic and Health Survey 2019: Key Indicators. Rockville, Maryland, USA: EPHI and ICF. 2019.

11. Roro MA, Hassen EM, Lemma AM, Gebreyesus SH, Afework MF. Why do women not deliver in health facilities: A qualitative study of the community perspectives in south central Ethiopia? BMC Res Notes. 2014;7(1):1-7.

12. Assefa Y, Gelaw YA, Hill PS, Taye BW, Van Damme W. Community health extension program of Ethiopia, 2003-2018: Successes and challenges toward universal coverage for primary healthcare services. Global Health. 2019;15(1):1-11.

13. Ethiopian Federal Ministry of Health. Health Sector Transformation Plan (2015/16-2019/20). Addis Ababa: Ministry of Health of Ethiopia. 2015. p. 1-118.

14. Bergen N, Zhu G, Yedenekal SA, Mamo A, Abebe Gebretsadik L, Morankar S, et al. Promoting equity in maternal, newborn and child health-how does gender factor in? Perceptions of public servants in the Ethiopian health sector. Glob Health Action. 2020;13(1).

15. Tolera, Moti J, Ahmed A, Hashi A, Tekilu A. Exploring barriers to reproductive, maternal, child and neonatal (RMNCH) health-seeking behaviors in Somali region, Ethiopia. PLoS One. 2019;14(3):1-15.

16. Tiruneh FN, Chuang K, Chuang Y. Women 's autonomy and maternal healthcare service utilization in Ethiopia. BMC Health Serv Res. 2017;17(718):1-12.

17. Wuneh AD, Medhanyie AA, Bezabih AM, Persson LÅ, Schellenberg J, Okwaraji YB. Wealth-based equity in maternal, neonatal, and child health services utilization: A cross-sectional study from Ethiopia. Int J Equity Health. 2019;18(1):1-9.

18. Solar O, Irwin A. A Conceptual Framework for Action on the Social Determinants of Health. Soc Determ Heal Discuss Pap 2 Policy Pract. 2010;79. 
19. Federal Minitry of Health of Ethiopia. Essential Health Services Package of Ethiopia. Addis Ababa: Ministry of Health of Ethiopia. 2019.

20. Patton MQ. Qualitative Research \& Evaluation Methods. 3rd ed. Thousand Oaks, CA, USA: SAGE Publication, Inc; 2002.

21. Matthew B. Miles, A. Michael Huberman JS. Qualitative Data Analysis: A Methods Sourcebook. 3rd ed. Thousand Oaks, CA, USA: SAGE Publications, Inc; 2014.

22. Adgoy ET. Key social determinants of maternal health among African countries: a documentary review. MOJ Public Heal. 2018;7(3):140-4.

23. Kea AZ, Tulloch O, Datiko DG, Theobald S, Kok MC. Exploring barriers to the use of formal maternal health services and priority areas for action in Sidama zone, southern Ethiopia. BMC Pregnancy Childbirth. 2018;18(1):1-12.

24. Abraha A, Myle'us A, Byass P, Kahsay A KJ. Social determinants of under-5 child health: A qualitative study in Wolkayit Woreda, Tigray. PLoS One. 2019;14(6):1-16.

25. Wong KLM, Brady OJ, Campbell OMR, Banke-Thomas A, Benova L. Too poor or too far? Partitioning the variability of hospital-based childbirth by poverty and travel time in Kenya, Malawi, Nigeria and Tanzania. Int J Equity Health. 2020;19(1):1-15.

26. Borde MT, Loha E, Johansson KA, Lindtjørn B. Financial risk of seeking maternal and neonatal healthcare in southern Ethiopia: a cohort study of rural households. Int J Equity Health. 2020;19(69):1-16.

27. Tekelab T, Chojenta C, Smith R, Loxton D. Factors affecting utilization of antenatal care in Ethiopia: A systematic review and meta-analysis. PLoS One. 2019;14(4):1-24.

28. Kiros M, Dessie E, Jbaily A, Tolla MT, Johansson KA, Norheim OF, et al. The burden of household outof-pocket health expenditures in Ethiopia: estimates from a nationally representative survey (201516). Health Policy Plan. 2020;1-8.

29. Blas E, Kurup AS. Equity, social determinants and public health programmes. Geneva: World Health Organization. 2010. 1-285 p.

30. Bedford J, Gandhi M, Admassu M, Girma A. "A normal delivery takes place at home": A qualitative study of the location of childbirth in rural Ethiopia. Matern Child Health J. 2013;17(2):230-9.

31. Çalışkan Z, Kılıç D, Öztürk S, Atılgan E. Equity in maternal health care service utilization: a systematic review for developing countries. International Journal of Public Health. 2015 Nov;60(7):815-25.

32. Tesfaye B, Mathewos T, Kebede M. Skilled delivery inequality in Ethiopia: To what extent are the poorest and uneducated mothers benefiting? Int J Equity Health. 2017;16(1):1-8.

33. Ochieng CA, Odhiambo AS. Barriers to formal health care seeking during pregnancy, childbirth and postnatal period: A qualitative study in Siaya County in rural Kenya. BMC Pregnancy Childbirth. 2019;19(1):1-14.

34. Hamal M, Hamal M, Hamal M, Dieleman M, Dieleman M, De Brouwere V, et al. Social determinants of maternal health: A scoping review of factors influencing maternal mortality and maternal health 
service use in India. Public Health Rev. 2020;41(1):1-24.

35. Oh JH. Educational expansion and health disparities in Ethiopia, 2005 - 2016. Soc Sci Med. 2019;235(May).

36. Daher-Nashif S, Bawadi H. Women's health and well-being in the united nations sustainable development goals: A narrative review of achievements and gaps in the gulf states. Int J Environ Res Public Health. 2020;17(3):1-8.

37. Kok MC, Kea AZ, Datiko DG, Broerse JEW, Dieleman M, Taegtmeyer M, et al. A qualitative assessment of health extension workers ' relationships with the community and health sector in Ethiopia: opportunities for enhancing maternal health performance. Hum Resour Health. 2015;13(80):1-12.

38. Bergen N, Abebe L, Asfaw S, Kiros G, Kulkarni MA, Mamo A, et al. Maternity waiting areas-serving all women? Barriers and enablers of an equity-oriented maternal health intervention in Jimma Zone, Ethiopia. Glob Public Health [Internet]. 2019;14(10):1509-23.

39. Wong KLM, Benova L, Campbell OMR. A look back on how far to walk: Systematic review and metaanalysis of physical access to skilled care for childbirth in Sub-Saharan Africa. PLoS One. 2017;12(9):1-20.

40. Tuyisenge G, Crooks VA, Berry NS. Facilitating equitable community-level access to maternal health services: exploring the experiences of Rwanda 's community health workers. Int J Equity Health 2019;4:1-10.

41. Tesfaye G, Chojenta C, Smith R, Loxton D. Delaying factors for maternal health service utilization in eastern Ethiopia: A qualitative exploratory study. Women and Birth. 2020;33(3):e216-26.

42. Pamela C. Banda, Clifford O. Odimegwu, Lorretta F. C. Ntoimo EM. Women at Risk: Gender Inequality and Maternal Health Women at risk. Women Health. 2017 Apr;57(4):405-429.

43. Konje ET, Hatfield J, Kuhn S, Sauve RS, Magoma M, Dewey D. Is it home delivery or health facility? Community perceptions on place of childbirth in rural Northwest Tanzania using a qualitative approach. BMC Pregnancy Childbirth. 2020;20(1):1-11.

44. Yargawa J, Leonardi-Bee J. Male involvement and maternal health outcomes: Systematic review and meta-analysis. J Epidemiol Community Health. 2015;69(6):604-12.

45. Manandhar M, Hawkes S, Buse K, Nosrati E, Magar V. Gender, health and the 2030 Agenda for sustainable development. Bull World Health Organ. 2018;96(9):644-53.

46. Tiruneh GT, Worku A, Berhane Y, Betemariam W, Demissie M. Determinants of postnatal care utilization in Ethiopia: A multilevel analysis. BMC Pregnancy Childbirth. 2020;20(1):1-12.

47. Tolera H. Risk factors for women 's non-utilization of decentralized primary health care facilities for postnatal care in rural western Ethiopia. Ther Adv Reprod Heal. 2020;14:1-19.

48. Tesfau YB, Kahsay AB, Gebrehiwot TG. Postnatal home visits by health extension workers in rural areas of Ethiopia: a cross- sectional study design. BMC Pregnancy Childbirth. 2020;20(305):1-9.

49. Dalinjong PA, Wang AY, Homer CSE. Has the free maternal health policy eliminated out of pocket payments for maternal health services? Views of women, health providers and insurance managers 
in Northern Ghana. PLoS One. 2018;13(2):1-19.

50. Fisseha G, Berhane Y, Worku A, Terefe W. Distance from health facility and mothers' perception of quality related to skilled delivery service utilization in northern Ethiopia. Int $\mathrm{J}$ Womens Health. 2017;9:749-56.

51. Sacks E, Masvawure TB, Atuyambe LM, Neema S, Macwan'gi M, Simbaya J, et al. Postnatal Care Experiences and Barriers to Care Utilization for Home- and Facility-Delivered Newborns in Uganda and Zambia. Matern Child Health J. 2017;21(3):599-606.

52. Chou VB, Walker N KM. Estimating the global impact of poor quality of care on maternal and neonatal outcomes in 81 low- and middle-income countries: A modeling study. PLoS Med. 2020;16(12):1-16.

53. Kruk ME, Gage AD, Arsenault C, Jordan K, Leslie HH, Roder-dewan S, et al. The Lancet Global Health Commission High-quality health systems in the Sustainable Development Goals era: time for a revolution. The Lancet. 2018;(18):1-57.

54. Bohren MA, Hunter EC, Munthe-Kaas HM, Souza JP, Vogel JP, Gülmezoglu AM. Facilitators and barriers to facility-based delivery in low- and middle-income countries: A qualitative evidence synthesis. Reprod Health. 2014;11(1):1-17.

55. Målqvist M, Thi D, Hoa P, Thomsen $S$. Causes and determinants of inequity in maternal and child health in Vietnam. BMC Public Health. 2012;12(641):1-10.

56. Ganle KK, Parker M, Fitzpatrick R, Otupiri E. A qualitative study of health system barriers to accessibility and utilization of maternal and newborn healthcare services in Ghana after user-fee abolition. BMC Pregnancy Childbirth. 2014;14(1):1-17.

\section{Supplementary Files}

This is a list of supplementary files associated with this preprint. Click to download.

- Additionalfile1.docx 